\title{
MOTIVAÇÕES EM COMPETIÇÃO NA VARIAÇÃO SOCIOLINGUÍSTICA: O PLURAL DOS PREDICATIVOS NA VARIEDADE DE SÃO JOSÉ DO RIO PRETO
}

\author{
Roberto Gomes CAMACHO* \\ Mircia Hermenegildo SALOMÃO **
}

- RESUMO: O objetivo deste trabalho é o de submeter a um tratamento variacionista, de base quantitativa, dados de marcação variável de plural no SN e no SA em contexto de predicativo, obtidos em córpus coletado na região de São José do Rio Preto. O trabalho procura examinar se a marcação de pluralidade nos predicativos pode ser explicada com base em motivações exclusivamente formais, ou exclusivamente funcionais, ou ainda, com base na interação entre ambas, que consistiriam, assim, em motivações em competição. Os resultados indicam que nem as motivações funcionais, nem as motivações formais regem solitariamente o fenômeno, que aparece fortemente condicionado por uma restrição externa específica, o grau de escolaridade. Por essa razão, a explicação mais plausível para a marcação de pluralidade nos predicativos é a de que há motivações em competição, nos termos de Du Bois (1985), e é a marcação de pluralidade o "bem limitado", pelo qual forças múltiplas, as motivações formais ou internas e funcionais ou externas, competem entre si.

- PALAVRAS-CHAVE: Funcionalismo. Formalismo. Pluralidade. Concordância nominal. Predicativo.

\section{Palavras iniciais}

A partir da década de 80, a sociolinguística variacionista passou a suspeitar teórico-metodologicamente do caráter explanatório do funcionalismo, entendido, porém, por Labov $(1987,1994)$ como restrito ao que Du Bois (1985) rotula "funcionalismo transparente". O resultado mais flagrante desse gesto foi adotar uma versão mais ou menos forte do estruturalismo autônomo, com a predominância de explicações formais e uma concepção autônoma de sintaxe.

Um aspecto que parecia necessário investigar é se não haveria um meio-termo entre essas duas tendências que pudesse amenizar posições tão antagônicas e

\footnotetext{
* UNESP - Universidade Estadual Paulista. Instituto de Biociências, Letras e Ciências Exatas. São José do Rio Preto - São Paulo - Brasil. 15054-090 - camacho@ibilce.unesp.br

** UNESP - Universidade Estadual Paulista. Instituto de Biociências, Letras e Ciências Exatas. São José do Rio Preto - São Paulo - Brasil. 15054-090 - mirciah@yahoo.com.br
} 
a resposta parecia advir do conceito de motivações em competição de Du Bois (1985). O objeto de estudos de uma teoria como a sociolinguística variacionista consiste em fenômenos de grande complexidade, pois o que motiva a variável são, por um lado, condições internas e externas e, por outro, condições internas formais e internas funcionais. É em função disso que se parecia adequar-se bem a ideia de que essa complexidade pudesse ser investigada como um jogo de motivações em competição.

Foram essas as razões que conduziram à proposição do projeto Motivações formais e funcionais da marcação de pluralidade no português falado na região de São José do Rio Preto, patrocinado pela FAPESP ${ }^{1}$ e desenvolvido entre 2006 e 2008. Os participantes impuseram a si mesmos investigar a marcação variável de número, entendida, na gramática normativa, como regras de concordância nominal e verbal, e numa variedade muito específica - a Amostra Iboruna (GONÇALVES, 2007; GONÇALVES; TENANI, 2008), que havia sido recentemente criada para suprir uma carência de dados sobre a realidade dialetal do interior paulista.

Com efeito, a sociolinguística brasileira, liderada pelo pioneirismo do Projeto Censo do Rio de Janeiro, transformado depois em Projeto PEUL, patrocinou um avanço considerável da pesquisa sociolinguística e, em consequência, do conhecimento da realidade sócio-dialetal do Brasil. No entanto, o conhecimento das variedades praticadas em São Paulo ainda era, há uma década, praticamente derivado de alguns trabalhos isolados e, por isso, longe de fornecer um quadro representativo da fala paulista.

Um passo decisivo para suprir essa lacuna foi a instituição, no ano de 2003, do projeto ALIP - Amostra Linguística do Interior Paulista (GONÇALVES, 2007), motivada pelos interesses de pesquisas que tinham como principal diretriz o enfoque da língua inserida em seu contexto social. O projeto ALIP não teve por objetivo o estudo de nenhum fenômeno particular; na realidade, assumindo para si uma concepção ampla e aberta dos possíveis fenômenos variáveis, procurou captar em grau máximo a diversidade linguística da região noroeste do estado de São Paulo, representada por São José do Rio Preto e seis outras cidades que lhe fazem fronteira: Bady Bassit, Cedral, Guapiaçu, Ipiguá, Mirassol e Onda Verde.

A constituição do Banco de Dados Iboruna (= rio preto, em Tupi), desenvolvida entre 2004 e 2007, representa dois tipos de amostras de fala: a primeira, coletada de acordo com os critérios da Sociolinguística laboviana (LABOV, 1972), constitui a Amostra Censo, e a segunda, coletada secretamente em contextos interacionais livres, sem controle de qualquer variável social (RONCARATI, 1996), constitui a Amostra de Interação.

\footnotetext{
Além do coordenador, constituiu-se uma equipe composta pelos seguintes bolsistas: Francielli Honorato Alves, William da Silva Santana, Ana Helena Rufo Fiamengui e Mircia Hermenegildo Salomão. Os desdobramentos práticos mais significativos dessa pesquisa foram as dissertações de mestrado dos dois últimos integrantes, apoiados, inclusive, com bolsas FAPESP, e a tese de doutorado em andamento de Mircia H. Salomão, também bolsista da mesma agência.
} 
Da uma perspectiva variacionista, que interessa aqui, os fenômenos de concordância já investigados contemplam os seguintes fenômenos: a marcação de plural em sintagmas nominais (FIAMENGUI, 2011) e em contextos de predicativo (SALOMÃO, 2010); a concordância verbal de 3PP (RUBIO, 2008) e padrões de concordância verbal e de alternância pronominal (RUBIO, 2012).

Fechado esse parêntese, retornemos ao projeto a que este trabalho se vincula. Como objetivo geral, o projeto Motivações formais e funcionais da marcação de pluralidade no português falado na região de São José do Rio Preto mirava a busca de razões teóricas e metodológicas que permitissem examinar que hipótese é a mais plausível para explicar a ausência e a presença de marcas de pluralidade nessa variedade. Por razões óbvias de espaço, o fenômeno enfocado neste trabalho se restringe aos SNs e SAs em estruturas predicativas.

A pergunta que se faz é se, na variedade estudada, a maior presença ou ausência de marcas tem motivação funcional em função de redundância, ou se tem motivação formal em função de repetição de estruturas em paralelismo formal; e ainda, alternativamente, se condições funcionais e formais competem entre si na motivação desse processo variável. Trata-se, como se vê, de reacender o debate teórico que se iniciou nos anos 80, momento em que a teoria sociolinguística teve que encarar críticas em função da expansão da análise variacionista ao estudo de variáveis do nível sintático (CAMACHO, 2003).

Tratando agora mais especificamente do objeto de estudo, é possível afirmar que os trabalhos realizados, na esteira da pesquisa pioneira de Poplack (1980) para o espanhol americano, tornaram possível formular princípios restritivos de natureza linguística e extralinguística na aplicação de regras variáveis como a de marcação de plural nos nomes. Esse trabalho propiciou um desenvolvimento acentuado do estudo da regra variável de concordância no português do Brasil a partir da década de 80. Os fenômenos que envolvem concordância são, muitas vezes, motivados por mecanismos de erosão fonológica, como processos de redução e/ou supressão consonantal, entre os quais se enquadra apagamento da marca de plural realizada por uma das pronúncias do arquifonema fricativo /S/.

É possível que os processos fonológicos de redução de segmentos fonológicos, como o de marcação de número no SN, possam ser acelerados por conta da redundância desse mecanismo flexional, com a presença de marca formal de plural em todas as palavras constituintes de um sintagma; haja vista a intuição clara de que o /S/ de palavras como lápis é frequentemente muito menos apagado do que núcleo de SNs como os meninos. Apesar dessa característica sintática, a variante padrão concorre, na prática quotidiana, com sentenças alternativas em que a indicação de pluralidade pode ocorrer num único constituinte, geralmente o que se localiza mais à esquerda do SN sujeito e, portanto, mais à esquerda da estrutura sentencial como um todo. Essa 
possibilidade pode reduzir a indicação de número a um único constituinte da sentença, comprometendo a expressão normativa tanto da regra de concordância nominal quanto da regra de concordância verbal.

Em predicativos com a mesma estrutura de SNs não predicativos, as restrições são as mesmas, mas outros fatores, como a marcação de plural no SN sujeito e no SV, interferem igualmente nesse processo variável, tratado nas gramáticas normativas como uma regra de concordância nominal e, como tal, de aplicação compulsória em todos os contextos de uso. Pode-se afirmar que o estudo dos predicativos em si não teve o mesmo sucesso que a pesquisa de outros tipos de sintagmas em termos de concordância nominal.

Além de ser mais reduzido o número de trabalhos, na dialetologia brasileira, sobre a marcação de plural no predicativo, torna-se praticamente uma necessidade incontornável a investigação dessa regra variável numa variedade dialetal ainda pouco conhecida, como a que se fala em uma parte da região noroeste do estado de São Paulo, nucleado em torno de São José do Rio Preto. Por isso, este trabalho se debruça sobre uma amostra de casos extraída do Córpus Iboruna, que justamente representa a fala dessa comunidade.

Este trabalho adota o modelo da Sociolinguística Quantitativa, aplicando-o a alguns princípios funcionalistas como a Condição de Distintividade (KIPARSKY, 1972) e o princípio de economia (HAIMAN, 1983), a fim de examinar as motivações (linguísticas e extralinguísticas) em competição (DU BOIS, 1985) na indicação de pluralidade nas estruturas predicativas da variedade selecionada. $\mathrm{O}$ artigo pretende discutir a natureza explanatória de motivações funcionais e de motivações formais para o enfoque de processos variáveis, restritos aqui à marcação variável de número em SNs e SAs de estruturas predicativas.

\section{A sociolinguística variacionista e a natureza formal e funcional da linguagem}

Se pensarmos no que o formalismo e o funcionalismo diferem mais nitidamente entre si, talvez seja no significado que cada qual atribui ao grau maior ou menor de autonomia da sintaxe. A concepção formalista estuda a linguagem como um sistema autônomo centralizado na sintaxe. O formalismo aposta suas fichas na autonomia da sintaxe em relação à semântica e à pragmática; para essa corrente, a prioridade vai da sintaxe à pragmática, via semântica. Já o funcionalismo vê os componentes mais visíveis da organização linguística - o pragmático, o semântico e o sintático como uma relação de maior ou menor grau de abrangência, mas em que é o primeiro o mais abrangente, dentro do qual se devem examinar os outros dois, com a exclusão de qualquer espaço para uma sintaxe autônoma (DIK, 1997). 
A relação entre a estrutura e a função linguística é estabelecida pelo enfoque funcionalista da variação em termos de motivações (CAMACHO, 2008). Dessa maneira, um linguista funcionalmente orientado assume que há motivações sistemáticas, que estão sujeitas a princípios regulares subjacentes à relação entre funções discursivas e estruturas morfossintáticas relevantes. As motivações são relacionadas ao modo como as estruturas se projetam nos conceitos correspondentes (iconicidade), à frequência e ao grau de acessibilidade dessas estruturas na mente (economia), à frequência e ao grau de acessibilidade de combinações individuais de estruturas e conceitos.

O princípio funcional de economia (HAIMAN, 1983) representa uma pressão para a simplificação máxima da expressão. A estrutura linguística torna-se, dessa forma, o mais opaca possível, contrapondo-se ao princípio da motivação icônica, que tende à transparência máxima entre forma e função. Pode-se entender o princípio de economia sintagmática como uma tendência para a redução do comprimento ou da complexidade do enunciado, de maneira que as expressões mais frequentes no uso tendem a reduzir-se fonologicamente e a informação redundante ou recuperável no contexto comunicativo tende a ser suprimida.

Situar a sociolinguística nesse quadro panorâmico deixa claro que a abordagem variacionista se inclui mais apropriadamente no espectro das tendências não formalistas, pois " [...] em sua fase inicial, a sociolinguística variacionista sustenta posições teórico-metodológicas que a distanciam da tendência formalista, inclusive como uma abordagem alternativa." (CAMACHO, 2008, p.19).

Na fase inicial, a sociolinguística variacionista reconhece a possibilidade teórica de que fatores sistemáticos do contexto social interfiram na estrutura linguística, mediante a implementação, a avaliação e a transição de variáveis linguísticas. Mais tarde, na fase em que o estudo da variação passou a tratar também de unidades morfológicas, a sociolinguística mantinha um forte comprometimento com compensações sistêmicas para perda de distinções funcionais relevantes, a chamada regra de mudança estrutural compensatória (Rule of Compensatory Structural Change) (LABOV, 1972).

Nos dialetos ingleses da Escócia, a simplificação de grupos consonantais com $t, d$ após oclusivas não sonoras tornou-se categórica conduzindo a um uso uniforme $a c^{\prime}$ por act e ap' por apt. Seria perfeitamente natural que a mesma regra eliminasse também a marcação de pretérito em liked e stopped, mas uma regra generalizada de epêntese eliminou o encontro consonantal, preservando os morfemas de pretérito dessas formas. Com esse exemplo, Labov (1972) pretendia argumentar que o sistema gramatical pode aproveitar-se de outras mudanças sonoras para prover o usuário de todas as necessidades comunicativas. 
Apesar dessa tendência francamente funcionalista na formulação inicial da sociolinguística variacionista e das substanciais descobertas de regularidades sob a égide da noção de regra variável, esse conceito entrou rapidamente no fogo cerrado da crítica, quando, na década de 70, o conceito foi estendido aos fenômenos sintáticos com os mesmos métodos aplicados aos fenômenos fonológicos.

\section{O compromisso da análise sociolinguística com explicações funcionalistas e formalistas}

Quando a variável se circunscreve a um fenômeno fonológico, o problema do significado não tem pertinência. No entanto, se a variável amplia seu escopo abarcando fenômenos sintáticos, é indiscutível a relevância do significado. Assim, quando os métodos e técnicas da investigação variacionista passaram a ser aplicados a casos de variação em sintaxe, irrompeu a primeira crise na metodologia do paradigma variacionista, em razão dos forte ataques desferidos por Lavandera (1978), Romaine (1981) e García (1985).

As críticas de Lavandera e García visaram o estatuto teórico da regra variável, quando aplicado à sintaxe. Já Romaine mirou o aspecto indutivista da teoria. Lavandera (1978) sustenta que é inadequado alargar a outros níveis de análise da variação o conceito de variável sociolinguística, que foi originariamente desenvolvida com base em dados fonológicos. Segundo a autora os estudos quantitativos da variação que se ocupam de alternâncias morfológicas, sintáticas e léxicas sentem falta de uma teoria bem organizada do significado.

Lavandera (1978) afirma que a análise da variação em fonologia pode ser admitida como uma contribuição para uma melhor compreensão dos tipos de significados, que podem comunicar diferenças formais; no entanto, a extensão da noção de variável para a variação não fonológica deixa de ser reveladora, pois para a autora há diferenças cruciais entre variáveis fonológicas e variáveis não fonológicas. As primeiras dispõem de significado social e estilístico e não precisam ter significado referencial. No entanto, as variáveis não fonológicas veiculam significado social e estilístico, mas também têm significado referencial. Lavandera (1978) destaca a dificuldade metodológica de se lidar com variáveis não fonológicas, principalmente por envolverem significação referencial.

Dessa maneira, a autora propõe relaxar a condição de que o significado referencial deve ser o mesmo para todas as alternativas, introduzindo, assim, uma condição de comparabilidade funcional, já que a equivalência semântica entre duas variáveis sintáticas implicaria numa redução drástica da noção de significado referencial. 
Labov (1978) não concorda com essa condição e nega a dificuldade da expansão das técnicas e métodos do modelo às variantes não fonológicas. Segundo o autor, muitas variáveis sintáticas não fornecem qualquer problema para o estabelecimento do mesmo significado representacional, bastando, para tal, reduzir o escopo do significado ao valor de verdade.

É o que fazem Weiner e Labov (1983): a escolha entre passiva não agentiva e ativa com agente genérico no discurso espontâneo deixa-os perfeitamente convencidos de que se trata aqui de uma variável sintática legítima em que as duas variantes têm o mesmo significado em termos de condições de verdade.

Mais recentemente, ao discutir o caráter funcional da mudança, Labov (1994) retoma e mantém essa mesma linha de argumentação. Em face da variação fonológica e morfológica, a hipótese funcional prevê a tendência de o falante selecionar uma variante ou outra de modo a preservar informação. A maioria dos resultados que discute mostra, ao contrário, que, no discurso corrente, a escolha entre variantes descarta a maximização de informação em favor de efeitos mecânicos, como condicionamento fonético e mera repetição de estruturas precedentes. Embora a mudança ameace a capacidade comunicativa, a maioria dos sistemas linguísticos se reajusta ao longo do tempo para preservar os meios de veicular informação.

Labov (1994) sustenta que a caracterização neogramática da estrutura linguística está de fato correta: como as leis fonéticas, a estrutura é um sistema predominantemente mecânico, fora do alcance do reconhecimento consciente ou do ajustamento de seus usuários. Como a linguagem é indubitavelmente programada para veicular informação proposicional, parece estranho que o falante não tenha liberdade de ajustar o sistema para maximizar a eficiência comunicativa.

Para o autor, uma explicação possível se assenta no fato de que a eficiência da linguagem depende de sua natureza automática e, por conseguinte, os esforços por mudá-la conscientemente devem confinar-se apenas a opções estilísticas de nível superior: a seleção de palavra e a construção de sintagmas e sentenças dentro de um conjunto estreitamente limitado de possibilidades.

\section{Fatores condicionadores como motivações em competição}

O breve tratamento das implicações de motivações de natureza funcional ou formal para a teoria variacionista envolve necessariamente a discussão da possibilidade de não se excluírem mutuamente, mas de competirem entre si. Quem primeiramente discutiu a noção de motivações em competição foi Du Bois (1985), que a vinculou à relação entre iconicidade e arbitrariedade. 
No arcabouço teórico do estruturalismo clássico, que Du Bois (1985) chama de "estruturalismo autônomo", a iconicidade é claramente considerada uma anomalia por operar contra a visão de que a linguagem é um sistema completamente autônomo com o conceito de arbitrariedade no centro. O principal arcabouço teórico a herdar de Saussure (1977) esse forte comprometimento com a autonomia da gramática é a teoria gerativa em suas diversas versões.

Em contraste com essa perspectiva, o "funcionalismo transparente" assume que fatores sintáticos aparentemente autônomos constituem, na realidade, os resultados transparentes dos objetivos funcionais do falante, de modo que não é necessário postular nenhum mecanismo sintático arbitrário para a língua (DU BOIS, 1985).

Na medida em que sejam reconhecidas como teorias, o estruturalismo autônomo e o funcionalismo transparente devem ser entendidos como inerentemente opostos e aparentemente irreconciliáveis; entretanto, estudos recentes em gramaticalização têm posto ênfase nas relações entre discurso e gramática, e tentado integrar parcialmente esses dois enfoques.

O estruturalismo autônomo estabelece uma forte distinção entre a linguística interna e a linguística externa. Entende Du Bois (1985) que essa distinção é necessária e é nela que o autor se apoia para mostrar que certos fenômenos podem ser simultaneamente imotivados a partir do ponto de vista sincrônico e motivados a partir de um ponto de vista metagramatical, que trata as gramáticas como sistemas adaptativos.

As gramáticas são, por um lado, parcialmente autônomas, e daí sistemas, e, por outro, parcialmente suscetíveis a pressões externas ao sistema, daí adaptativas. Segundo Du Bois (1985), essa distinção é metodologicamente útil apenas se dermos pleno reconhecimento à existência de motivações em competição e desenvolvermos um arcabouço teórico que, inicialmente, descreva e analise a interação das motivações com contextos específicos e, posteriormente, seja capaz de prever a resolução da competição entre elas.

Em primeiro lugar, para duas motivações competirem no mesmo âmbito funcional deve haver o que Du Bois (1985) chama de "bem limitado", pelo qual elas competem. O "bem limitado" é o domínio da forma linguística, sobre as quais forças motivadoras múltiplas não podem prevalecer completamente.

Duas motivações que competem para o controle de um único paradigma linguístico, categoria ou morfema podem ser tanto ambas internas quanto ambas externas ou mesmo pode ocorrer que uma das motivações seja interna enquanto a outra seja externa. Segundo Du Bois, a avaliação do significado da teoria linguística se dá a partir de uma perspectiva que vê as gramáticas como sistemas adaptativos e que, portanto, reconhece, em primeiro lugar, a interação entre forças internas e 
externas. Quando as forças que se originam de fenômenos externos penetram no domínio da língua, elas encontram e interagem com as forças internas.

Dizer que a língua é adaptativa por responder a pressões do contexto externo, implica de pronto rejeitar a teoria do estruturalismo autônomo, que é limitada na tentativa de explicar a estruturação de uma língua, por reconhecer apenas forças motivadoras internas. Dizer, por outro lado, que a língua é um sistema, e que, como tal, tem certo grau de continuidade de existência, implica rejeitar o arcabouço teórico do funcionalismo transparente, que falha em explicar o fato de que categorias gramaticais podem ser preservadas, por assim dizer, numa forma mais ou menos congelada. Mais importante ainda que isso talvez, ele falha em construir apropriadamente o aspecto interno mais fundamental da gramática, o processo de gramaticalização em si mesmo.

A compreensão dessas diferenças tem uma importância fundamental para os objetivos desta pesquisa, pois, em grande medida, foram essas razões teóricas que organizaram os procedimentos metodológicos para o processamento dos dados, ou seja, com base em uma metodologia que favorecesse o enfoque da marcação de pluralidade nas estruturas predicativas a partir de duas diferentes perspectivas, a formal e a funcional. A dimensão formal explica as motivações internas, enquanto a dimensão funcional, acrescida dos fatores extralinguísticos, explica as motivações externas. Nesse caso, o "bem limitado", na visão de Du Bois (1985), é o domínio da variável em busca de resolução seja em direção da categoricidade, mediante predomínio de uma das variantes, seja em direção de estabilidade, mediante distribuição por diferentes comunidades sociais como indício de identidade cultural.

\section{A literatura sobre marcação de pluralidade}

De acordo com a norma padrão do português brasileiro, o fenômeno de concordância é considerado regra obrigatória. Como a concordância reitera marcas contendo a mesma informação em pontos diversos da cadeia sintagmática, a variante padrão é necessariamente redundante.

Por outro lado, é também verdadeiro ser a concordância de número uma variação marcada pela identidade social do falante e por motivações emanadas do contexto social. Uma motivação potencialmente relevante para não se usar a regra de concordância nominal é o baixo nível de escolaridade, que impede as pessoas de familiarizar-se suficientemente com a pressão normativa exercida pelo sistema escolar; outra motivação potencialmente relevante é a situação discursiva: mesmo falantes com alto grau de escolaridade não aplicam a regra de concordância em circunstâncias mais informais de uso. Assim, o modo categórico 
como a tradição gramatical concebe a variação de pluralidade não se aplica de fato ao uso da língua no contexto social.

Como se sabe, à medida que a língua varia, é possível expressar um mesmo enunciado de modo diferente sem mudar o seu significado, como nas sentenças contidas em $1(a-b)$
(1) a os orelhão (Ø) de lá não é igual (Ø) aqui (AC029/NE/L.069)
b os orelhões de lá não são iguais aos daqui

Na alternativa contida em (1a), a marca formal de pluralidade se encontra apenas no determinante, enquanto na contida em (1b) as marcas formais de pluralidade estão presentes no determinante e no núcleo do SN sujeito e do predicativo, além da marcação na cópula verbal. A ausência de marcas não é obstáculo para que, ainda assim, seja assegurada a noção de pluralidade sem provocar nenhuma ambiguidade tendo em vista a marcação de número no determinante.

É possível afirmar, então, que, de um ponto de vista funcional, a explicitação de pluralidade no determinante poderia tornar desnecessárias as marcas nos outros constituintes, por razão de economia, em função da redundância inerente da regra de concordância nominal na variedade padrão. Outra explicação possível seria uma motivação por reiteração de formas em paralelismo, tanto na marcação quanto na ausência de marcação (SCHERRE, 1988).

Esse modo variável de marcar número leva a refletir sobre que motivação estaria em jogo no processo de variação da concordância nominal: (i) o paralelismo formal, na medida em que a indicação de pluralidade explícita, ou não explícita, levaria em conta a marcação do mesmo tipo na posição anterior; (ii) a condição funcional de distintividade (KIPARSKY 1972), na medida em que a indicação redundante a partir do constituinte marcado acionaria a desnecessidade de outras marcas subsequentes sem risco de ambiguidade referencial.

Seria possível também supor que poderia haver motivações em competição (DU BOIS, 1985), de natureza interna, ou formal, e externa, ou social. Nesse caso, seria possível supor que os casos alternativos que não apresentam todas as marcas de plural podem representar a escolha de diferentes grupos sociais. Desse modo, haveria grupos sociais em que predominaria a escolha de SNs nominais com marcas formais de plural e, em contraste, outros grupos sociais para os quais a presença de todas as marcas nem sempre é necessária.

As investigações no espanhol cubano realizadas por Terrel (1975) sobre as condições funcionais da supressão do marcador de plural permitiram constatar que os falantes cubanos evitam suprimir todos os traços de indicação morfológica 
de número, preservando, dessa maneira, a primeira forma da estrutura sentencial. Outros trabalhos, como o de Braga (1978), com córpus coletado na região do Triângulo Mineiro, confirmam que o determinante, que geralmente ocupa a primeira posição no SN, é a categoria em que mais é observada a retenção da marca de número.

No entanto, essa posição foi amplamente reformulada por Scherre (1988), mediante a reanálise do mesmo fenômeno. A autora rejeita a ideia de que posição do constituinte seja o fator determinante da marcação de pluralidade no SN, mostrando que posição e categoria gramatical são condições fortemente entrelaçadas para a determinação de marca de número no sintagma nominal.

A autora postula um princípio mais geral, baseado na constatação de que, no SN, marca leva à marca e zero leva a zero, princípio esse que denominou de "paralelismo formal". Ao postular esse princípio, Scherre (1988) recusa também a atuação da Condição de Distintividade de Kiparsky (1972), considerada por ela como uma hipótese funcionalista no arcabouço da teoria gerativa.

Em seus estudos, Kiparsky (1972) se concentra num fenômeno fonológico encontrado em algumas variedades do inglês norte-americano mediante o qual se apaga variavelmente o fonema /t/ em final de palavra. Quando esse fenômeno fonológico atua como marca de pretérito, o fonema é cancelado somente nos casos de verbos irregulares, cujas formas de presente e de pretérito contêm uma vogal diferente na raiz, como no caso de keep vs. kep(t). Pode-se afirmar que a regra de apagamento é bloqueada ou aplicada em menor grau quando sua aplicação neutraliza a distinção entre a forma do presente e a do pretérito, como em passed, e é liberada quando a distinção se mantém devido à alternância vocálica na raiz (KIPARSKY, 1972). Na tentativa de explicar esse fenômeno variável, o autor postula esse princípio funcional, a Condição de Distintividade, que se caracteriza como uma tendência pela retenção de uma informação semanticamente relevante na estrutura superficial.

Poplack (1980) foi uma das primeiras pesquisadoras a incorporar esses princípios aos estudos sociolinguísticos. A autora investiga a influência de condições formais e funcionais competindo pela marcação variável de plural no espanhol porto-riquenho. Poplack (1980) reivindica a superioridade das condições estruturais para a explicação desse fenômeno variável. Sua pesquisa revela evidências de uma tendência local, isto é, de uma tendência para a concordância no nível da sequência: a ausência de um marcador no segmento precedente à ocorrência favorece a supressão neste elemento, enquanto a presença de uma marca imediatamente precedente favorece a retenção de uma marca na ocorrência. Isso mostra que, se a cadeia manifestar a supressão de marcas nos dois primeiros constituintes, é significativa a contribuição do fator "posição" para a probabilidade de supressão no terceiro elemento. Se a sequência for realizada com 
marcas na primeira e na segunda posição, é bem reduzido o efeito da supressão no constituinte da terceira posição. O resultado é, enfim, exatamente oposto do que se descobriu em outros estudos, e é caracterizado por Labov (1994) como um argumento contrafuncional.

Hochberg (1986) retoma a hipótese de Kiparsky (1972) no estudo da variedade porto-riquenha do espanhol, cujos resultados seguem uma direção oposta aos de Poplack (1980), confirmando, assim, a atuação da Condição de Distintividade para a explicação do mesmo fenômeno. Entretanto, em estudo parecido ao de Poplack (1980), Guy (1981) não encontra, nos seus dados sobre o português brasileiro, respaldo para a confirmação da hipótese funcionalista, e acaba postulando que as restrições funcionais atuam apenas quando forma e função são perfeitamente paralelas (GUY, 1981).

Lefebvre (1981), estudando o Quéchua de Cuzco, apresenta também evidências de restrições funcionais e não funcionais em competição, mostrando que algumas situações são previstas pela hipótese funcionalista de Kiparsky e outras não (LEFEBVRE, 1981).

O paralelismo formal foi absorvido como princípio teoricamente explanatório por Labov (1994) como forma de rejeição simultânea de princípios funcionalistas, um movimento que repercutiu largamente na teoria variacionista. Resta, portanto, saber se procedimentos mecânicos sempre sobrepujam os funcionais que requerem marca de pluralidade quando o processo de comunicação exigir eficiência informativa ou se representam motivações competindo entre si, como Lefebvre (1981) sugere para o Quéchua.

\section{Composição da amostra e definição dos condicionamentos da variável}

O universo de pesquisa deste trabalho é composto por um recorte do Banco de Dados Iboruna², contendo 128 de 152 gravações das Amostras Censo (GONÇALVES, 2007; GONÇALVES; TENANI, 2008). O recorte aqui realizado se justifica pela ausência, na pesquisa original (SALOMÃO, 2010) da faixa etária de 7 a 15 anos e, portanto, pela preferência por trabalhar com uma apreensão mais consolidada da norma padrão. Cada Amostra Censo é composta por cinco gêneros textuais: narrativas de experiência pessoal, relato de narrativa recontada, relato descritivo, relato de procedimento $e$ relato de opinião.

A constituição da amostra provém da gravação de 152 informantes, cujo perfil é determinado pela combinação de fatores sociais: gênero/sexo, escolaridade, faixa

\footnotetext{
Apesar de o Banco de dados Iboruna possuir Amostra de Interação (AI) e Amostra Censo (AC), incorporou-se o segundo tipo de amostra, pois os fatores sociais nas Amostras de Interação não foram controlados, uma vez que as gravações foram feitas anonimamente e sem o conhecimento prévio dos informantes.
} 
etária e classe social (renda familiar). Desse modo, os grupos de fatores sociais têm a seguinte constituição:

\section{Tabela 1 - Grupos de fatores sociais.}

\begin{tabular}{ll}
\hline Grupo de fatores & Fatores \\
\hline 1 - Sexo/ gênero & masculino; feminino \\
2 - Faixa etária & 16 a 25 anos; 26 a 35 anos; 36 a 55 anos; mais de 55 \\
3 - Escolaridade & $1^{\circ}$ ciclo do Ensino Fundamental; $2^{\circ}$ ciclo do Ensino Fundamental; Ensino \\
& Médio; Ensino Superior \\
\hline
\end{tabular}

\section{Fonte: Elaboração própria.}

A investigação da marcação de pluralidade na variedade falada na região de São José do Rio Preto se restringe aqui à análise de um envelope de variação constituído pela variável binária "presença ou ausência de marcação de pluralidade em SNs e SAs predicativos", formalizada, basicamente, como $<\mathrm{S}>$, representando o arquifonema /S/. Essa categoria representa, por sua vez, as variantes presença ou ausência de qualquer realização fonética, com alterações morfofonêmicas da marca de pluralidade.

No português brasileiro, presença e ausência de plural se alternam na língua falada em posição final de palavra, contexto que apresenta grande potencial de variação em função de um processo de erosão fonológica por distensão dos órgãos fonadores em posição átona. Essa regra é aplicada tanto em palavras monomorfêmicas (como lápis, menos) quanto em palavras bimorfêmicas (como casas, patos, meninas). Mesmo representando um morfema de plural, a redundância de marcação no SN leva a uma supressão maior da fricativa em contextos de palavras bimorfêmicas do que em palavras monomorfêmicas.

O contexto de análise dessa variável é representado pela posição sintática de predicativo, que pode ser representada por SNs ou SAs de um único elemento (substantivos, adjetivos, tomados como elementos predicadores propriamente ditos, como mostram (3a-b) e particípios em estruturas passivas, como mostra (2). Nos exemplos contidos em (3a-b), o predicativo é também acompanhado por palavras invariáveis, que aparecem grifadas.

(2) a sala de aula de terce(i)ra e quarta séries são salas onde não existe alfabeto... porque os alunos já estão alfabetizados... (AC 88/ L 335336/ DE) 
(3) a (..) mas as casas ali são bem antigas... né?... (AC 120/ L 266/ DE)

b (...) que nós falávamos que a S. num era boa pesso::a... que num era boa companhi::a... aí diz que o marido dela respondia assim - "imagina eles são muito sistemático eles tão com inVEJA dela" (AC 050/ L 134-136/ NR)

Selecionadas as ocorrências, cada uma delas foi analisada segundo os critérios definidos nos grupos de fatores relacionados a seguir, os quais constituem os contextos variáveis definidos para a discussão neste trabalho. Os parâmetros de análise, cuja base teórica se assenta nos trabalhos de Scherre (1988, 1991, 1994) e no de Dias (1996), vão ser apresentados paralelamente à apresentação dos resultados. Para o tratamento quantitativo dos dados, usou-se o Pacote Estatístico Goldvarb (SANKOFF; TAGLIAMONTE; SMITH, 2005).

\section{Motivações internas e externas da marcação de número no SN/SA predicativo}

A amostra constitui-se de um total de 526 ocorrências com estruturas predicativas, que revelam a aplicação da regra de $\mathrm{CN}$, dentre os quais $58,0 \%$ (310/526) apresentam marcas de plural, enquanto 42,0\% (216/526) não apresentam aplicação da regra de concordância nominal (SALOMÃO, 2010).

Os resultados serão apresentados em tabelas vistos da perspectiva do valor da aplicação da regra, ou seja, da presença de marcas formais nas estruturas predicativas. Conforme se verá, o exame do Princípio de Paralelismo Formal pode ser visto em duas dimensões: na dimensão intraoracional e na dimensão interoracional ou discursiva.

$\mathrm{Na}$ dimensão intraoracional, as estruturas predicativas são vistas em sua relação com outras categorias sintáticas da oração. Como deveriam ser supostamente marcadas com base na regra de concordância nominal da variedade padrão, essas categorias deveriam ativar a marcação na forma do predicativo. Essas categorias são o sujeito e o verbo, que em geral se confina com a cópula ser.

$\mathrm{Na}$ dimensão interoracional ou discursiva, o princípio do paralelismo formal é visto como a repetição de estruturas similares, cujo escopo, nesse caso, é o de uma oração inteira contendo o fenômeno em análise com formas similares que podem recorrer ou não no discurso corrente.

A trajetória de análise se inicia com a dimensão intraoracional, mas, ainda mais especificamente, com as características formais do sujeito, vistas em sua relação 
com a estrutura predicativa, isto é, examina-se a marcação de plural na estrutura predicativa em correlação com uma configuração flexional similar no sujeito.

O que se busca investigar é a confirmação ou não da hipótese formal de que a presença ou ausência de marcas conduz a uma configuração recorrente no predicativo; na situação inversa, em que essa hipótese seria rejeitada, é necessário verificar se há outro princípio funcional implícito, como a Condição de Distintividade (KIPARSKY, 1972).

Nesse parâmetro, considera-se não explícitos todos os tipos de sujeito considerados por Scherre $(1988,1991,1994)$ como nulo e desinencial, conforme mostra (4a). Os casos de manifestação explícita do SN sujeito incluem situações como a de (4b) em que todos os elementos nominais flexionáveis ou somente os últimos estão marcados com plural e em que a última marca está neutralizada em função do contexto fonológico seguinte. Em (4c) aparecem situações em que ou o sujeito explícito é privado da(s) última(s) marca(s) formal(is) explícitas de plural ou o sujeito explícito é coordenado por constituintes no singular. Em (4d) aparece uma situação em que o sujeito explícito tem marca semântica de plural (nós e numerais isolados). Finalmente, em (4e), o sujeito explícito aparece com marca formal de plural totalmente neutralizada.

(4) a então nós casamos e:: a gente trabalhava muito né?... mas éramos felizes passeávamos... e viajávamos muito (AC 138/NE/L.15-16)

meus pais são bastante são evangélicos né?... (AC035/NR/L.202)

b as avenidas as avenidas são largas sabe bem espaçosa é um lugar limpo... (AC045/DE/L.251-252)

minha vó num queria o namoro porque na época éh...as coisa era muito rígida... (AC034/NR/ L.42)

C num tinha muita informação dentro de casa... porque meu pai e minha mãe sempre foi muito crente... (AC 036/ L 229/ NR)

d aí surgiu a briga... mas hoje nós é colega normal (AC065/NE/L.29) então é bem gostoso... e lá também... éh:: eles são bem unidos então... tem sempre... um pessoal da nossa idade... (AC46/DE/L.276-277)

A Tabela 2 mostra os resultados quantitativos da relação entre estrutura predicativa e as características formais do sujeito acima descritas. 


\section{Tabela 2 - Características formais do sujeito e pluralidade na estrutura predicativa.}

\begin{tabular}{|c|}
\hline Fatores \\
\hline Sujeito não explícito (desinencial ou nulo) \\
\hline $\begin{array}{l}\text { Sujeito explícito com marca formal de plural totalmente } \\
\text { neutralizada }\end{array}$ \\
\hline $\begin{array}{l}\text { Sujeito explícito: (i) com todos os elementos nominais } \\
\text { flexionáveis marcados; (ii) com os últimos elementos com } \\
\text { marca formal de plural; (iii) ou com a última marca } \\
\text { neutralizada por contexto fonológico seguinte. }\end{array}$ \\
\hline
\end{tabular}

\begin{tabular}{lll} 
Freq. & \% & PR \\
\hline $39 / 56$ & 69 & $\mathbf{. 6 4}$
\end{tabular}

$30 / 45$

66

.55

Sujeito explícito com marca semântica de plural (nós e

$219 / 330$

$\begin{array}{ll}66 & \mathbf{5 2}\end{array}$

numerais isolados)

$36 \quad .39$

Sujeito explícito sem as últimas marcas formais explícitas de plural ou sujeito coordenado singular

\section{Total}

$10 / 62$

16

.27

$310 / 526$

$59 \quad \mathbf{5 9 5}$ (input)

\section{Fonte: Elaboração própria.}

Os resultados da Tabela 2 são reveladores. Supondo que o sujeito contivesse todas as marcas formais de plural, seria de esperar que o predicativo também dispusesse de alto grau de marcação de pluralidade. No entanto, essa expectativa não se confirma, já que na situação em que o sujeito contém todas as marcas formais explícitas, é provável haver marcação formal na estrutura predicativa, mas com uma frequência (PR .52) que beira o limite da neutralidade.

No entanto, uma tendência oposta se verifica nos casos em que a estrutura predicativa é precedida por um sujeito explícito desprovido das últimas marcas formais, ou por um sujeito coordenado. A reduzida incidência de marcas formais no predicativo, (PR .27), indica que o princípio atua mais no sentido de ausência de marca ativar ausência do que presença de marca ativar presença.

Esse resultado é recorrente, já que, nas situações em que o sujeito explícito contém marca semântica de plural, como pronomes de primeira pessoa do plural e numerais, a probabilidade de a estrutura predicativa ser marcada formalmente é também reduzida, como indica o PR de 39.

Já nas situações em que a estrutura predicativa for precedida por um sujeito explícito com marca formal de plural neutralizada, o comportamento quantitativamente evocado é para uma tendência discreta de marcação de pluralidade, já que próximo da neutralidade (PR .55). Como as marcas estão neutralizadas, principalmente por causa da proximidade com o verbo ser, não é 
possível descrever, sem um aparato acústico adequado, se o informante emite ou não a marca de pluralidade. Desse modo, é como se o sintagma nominal apresentasse todas as marcas, numa análise simples, de oitiva.

É, por outro lado, curioso observar que a maior probabilidade estatística (.64) de marcação se aplica aos casos em que o sujeito é não explícito, isto é, desinencial ou nulo. Curioso, porque aponta para uma tendência oposta, como uma motivação funcional, já que, se o Princípio de Paralelismo Formal tivesse uma atuação consistente, aplicando-se de modo constante e regular, seria de esperar que sujeitos zeros, no caso dos nulos, acionassem ausência de marcas no predicativo e, inclusive, até menos marcas que os casos submetidos a outros fatores. Todavia, os dados parecem preservar a intuição de que, na ausência de marca formal no sujeito, alguma pluralidade tem que ser marcada em algum outro lugar da estrutura da oração e esse lugar acaba sendo a estrutura predicativa. Essa é uma evidência de que o comportamento dos informantes tende mais favoravelmente para a preservação de informação.

Esses resultados mostram que, na variedade riopretense, o Princípio de Paralelismo Formal, aplicável aos dados de Scherre (1988) para a variedade carioca, parece não ser a única motivação para a marcação de pluralidade na estrutura predicativa, e, portanto, parece não ter poder explanatório suficiente para explicar o processo variável em questão no Córpus Iboruna. Ou, pelo menos, o máximo que pode se inferir desses resultados é que pouco é possível deduzir deles a respeito de que princípio atua mais vigorosamente para marcar ou não marcar o constituinte em função de estrutura predicativa nos dados do Iboruna: se a Condição de Distintividade ou se o Princípio de Paralelismo Formal; mais provável é que constituam motivações em competição atuando como duas forças em sentido contrário.

Passemos, agora, a examinar outro aspecto parcial que pode indicar a atuação do Princípio de Paralelismo Formal: a relação entre pluralidade explícita na estrutura predicativa e as características formais do verbo.

A expectativa em torno dessa variável seria testar a possível atuação do Princípio de Paralelismo Formal, que se deduz da comparação entre os fatores formalmente diferentes, mas inter-relacionados. Em outros termos, a marcação de plural na estrutura predicativa em correlação com a mesma configuração flexional no verbo tem a finalidade de testar a hipótese formal de que a presença ou ausência de marca de plural no verbo implica configuração formalmente recorrente na estrutura predicativa. Uma relação inversamente proporcional nos dois casos não permitiria admitir a hipótese formal.

Nessa fotografia parcial do paralelismo formal, o fenômeno em análise é visto em sua relação com o verbo, que pode, por conseguinte, não manifestar-se 
explicitamente, como (5-a), ou, alternativamente, manifestar-se explicitamente com marca formal de plural como (5-b) ou sem marca formal de plural com (5-c).

(5) a do meu marido... são um amor de pessoas [Ø] super hospitaleiro (AC028/NE/L.54-56)

$\mathrm{b}$

porque:.: é aquela coisa né? a maioria das pessoas são preconceituosas quan/... quanto a pessoas crentes né? ... (AC45/NE/L.19-20)

C

minha vó num queria o namoro porque na época éh...as coisa era muito rígida... (AC034/NR/ L.42)

Os resultados relativos a esse grupo de fatores estão expostos na Tabela 3.

\section{Tabela 3 - Relação entre as características formais do verbo e a marcação de pluralidade.}

\begin{tabular}{rrrr}
\hline Fatores & Freq. & $\mathbf{( \% )}$ & PR \\
\hline Verbo sem marcas & $7 / 78$ & 9 & $\mathbf{. 1 4}$ \\
Verbo com marcas & $288 / 426$ & 67 & $\mathbf{. 5 7}$ \\
Zero Verbal & $15 / 22$ & 68 & $\mathbf{. 6 5}$ \\
\hline Total & $310 / 526$ & 59 & $\mathbf{. 5 9 5}$ (input) \\
\hline
\end{tabular}

Fonte: Elaboração própria.

À primeira vista, os resultados mostram influência positiva do paralelismo formal. Se, por um lado, a presença de marcas formais explícitas no verbo ativa positivamente a formulação de estruturas predicativas com marcas formais explícitas (.57), por outro, o inverso também é verdadeiro: a ausência de marca formal no verbo é diretamente proporcional à ausência de marca no predicativo (.14).

É necessário observar, no entanto, que a incidência de marcas no predicativo com verbo flexionado tem uma frequência discreta (.57) e que, além disso, os casos de zero verbal ativam um grau muito elevado de marcação de plural na estrutura predicativa com o índice de aplicação de regra atingindo seu ápice (.65). O contexto de justaposição entre sujeito e estrutura predicativa parece reforçar a marcação de natureza estilisticamente formal da construção, fato que deve favorecer a marcação de pluralidade.

No entanto, é necessário ver esses dados de uma perspectiva mais abrangente que envolva variáveis externas principalmente em função da importância que 
a escolaridade formal tem no Brasil. Dessa maneira, afirmar que a presença de marcas no predicativo, quando não houver verbo na sentença, seja apenas o resultado da atuação do Princípio de Paralelismo Formal pode não ser ainda uma conclusão definitiva.

Vale lembrar a esse respeito que, majoritariamente, as ocorrências com verbo sem marca explícita de plural dispõem de uma ou duas marcas formais no SN sujeito. É possível deduzir, portanto, nesse caso, que informação já fornecida não precisa ser repetida nem no verbo nem no predicativo, sem incorrer em qualquer risco de ambiguidade referencial, como mostram os exemplos (6a-b).

a

(...) minha vó num queria o namoro porque na época é as coisa era muito rígida... (AC 034/NR/L.42)

b (...) porque:: naquela época num era que nem hoje que os bastardo era reconhecido cê tinha que brigar muito (AC 100/NR/L.119)

Vale a pena salientar que, mesmo nos casos em que é relativamente majoritária a aplicação do Princípio de Paralelismo Formal, o efeito não tem um escopo categórico, isto é, não é reconhecido por toda a comunidade linguística, mas representa apenas uma tendência estatisticamente significativa em favor da aplicação positiva de concordância no predicativo.

O que se deve reter aqui é que a maior parte dos casos revela que a presença de marcas no sujeito aciona a pluralidade no verbo; similarmente, quando o sujeito não dispuser de todas as marcas formais, é frequente o uso de verbos também não flexionados. Essa correlação entre as marcas do sujeito e do verbo acaba por provocar efeito paralelo no predicativo.

Uma terceira dimensão do paralelismo formal, que, como grupo de fatores, foi estatisticamente selecionado pelo programa Goldvarb, tem a ver com o número de marcas precedentes no sujeito e no verbo. Não havendo marca formal de plural em todos os constituintes do SN e no verbo, é provável que a estrutura predicativa seja marcada, caso o comportamento dos informantes seja guiado pelo princípio da economia (HAIMAN, 1983) e/ou da Condição de Distintividade de Kiparsky (1972). Os resultados dessa análise estão contidos na Tabela 4. 
Tabela 4 - Número de marcas precedentes no sujeito e no verbo.

\begin{tabular}{|c|c|c|c|}
\hline Fatores & Freq. & $(\%)$ & PR \\
\hline Três ou mais marcas & $149 / 188$ & 79 & .65 \\
\hline Duas marcas & $115 / 214$ & 53 & .44 \\
\hline Uma marca & $46 / 124$ & 37 & .36 \\
\hline Total & $310 / 526$ & 59 & .595 (input) \\
\hline
\end{tabular}

\section{Fonte: Elaboração própria.}

Os resultados apontam muito mais para a confirmação da atuação positiva do Princípio de Paralelismo Formal do que para o de economia ou da Condição de Distintividade, já que a incidência de marcação formal na estrutura predicativa é diretamente proporcional ao número de marcas precedentes em outros constituintes da sentença.

Há, no entanto, uma ressalva importante a fazer: o peso relativo tem significação estatística apenas para a aplicação do fator três ou mais marcas (.65). Nesse caso, constituintes precedentes com duas marcas ou com uma única marca desfavorecem a aplicação da regra de concordância na estrutura predicativa. Vale a pena indagar, portanto, por que razão uma ou duas marcas precedentes não favoreceriam a aplicação da regra nos mesmos termos em que favorecem três ou mais marcas precedentes. Haveria aí motivações em competição?

Passemos, agora, à análise de outra dimensão do paralelismo formal, que é a que se opera no discurso, uma forma de estender a atuação desse princípio do nível da sentença para o nível do discurso. Por paralelismo formal no discurso, entende-se a recursividade ou não da construção em análise. Ou o fenômeno aparece isolado, como em (7a), ou aparece em série, como o primeiro, como em (7b), ou como o segundo ou terceiro da série, podendo, nesse caso, ser precedido de outra construção cuja estrutura predicativa tem plural explícito, como (7c), ou plural zero, como (7d).

(7) a (...) é bonito as praias são bonitas mas a cidade assim o centro assim... é muito... é muito poluído assim... (AC 044/DE/L 164-165)

b (...) sessenta por cento dos brasile(i)ros são católicos...Desses sessenta só cinco por cento são praticantes...né? (AC023//L.544-545)

c (...) eu acho que as crianças tão muito assim... éh:: desorienta::das éh éh só pensam nisso malemá estão fican(d)o mocinhos já ...já tão atrás disso... (AC38/RO/L. 253-255)

d (...)aí ela falo(u) pra mim - "não nós tá brigado tal cê a::.cha todo mundo sabe que nós tá brigado... (AC019/NE/L.10-11) 
Diferentemente, porém, do paralelismo entre constituintes no nível interno da sentença, a ideia subjacente a esse grupo de fatores é a de que uma estrutura predicativa formalmente marcada na construção precedente favoreceria a marcação formal na estrutura predicativa das construções seguintes; o inverso também seria verdadeiro: estruturas predicativas sem marcas formais de plural na construção precedente refreariam a aplicação da CN na estrutura predicativa das construções seguintes. Os resultados dessa análise estão contidos na Tabela 5.

\section{Tabela 5 - Relação entre paralelismo formal no discurso e marcação de pluralidade.}

\begin{tabular}{|c|c|c|c|}
\hline Fatores & Freq. & $\%$ & PR \\
\hline $\begin{array}{l}\text { Estrutura predicativa precedida de estrutura predicativa } \\
\text { com plural explícito }\end{array}$ & $62 / 67$ & 92 & .85 \\
\hline Estrutura predicativa primeira de uma série & $55 / 87$ & 63 & .54 \\
\hline Estrutura predicativa isolada & $187 / 331$ & 56 & .46 \\
\hline $\begin{array}{l}\text { Estrutura predicativa precedida de estrutura predicativa } \\
\text { com plural zero }\end{array}$ & $6 / 41$ & 14 & .10 \\
\hline Total & $310 / 526$ & 59 & .595 (input) \\
\hline
\end{tabular}

Fonte: Elaboração própria.

Os resultados mostram que, na série, uma estrutura predicativa precedida de outra similar com marcas de plural recebe um alto índice de marcação formal (.85) e, ao contrário, uma estrutura predicativa precedida por estrutura congênere destituída de marcação formal terá maior probabilidade ainda de não receber marca formal (.10). Portanto, na variedade analisada, a aplicação da regra de CN parece ser severamente condicionada por esse fator.

Neutraliza-se muito esse efeito nas situações em que a estrutura predicativa for a primeira de uma série de outras construções com predicativo/particípio passivo: os dados apontam para uma tendência de marcação de pluralidade, mas, com um PR próximo de .50, tendência quantitativa que beira a neutralidade. Nas situações de predicativos isolados no discurso, fica estatisticamente mais evidente a probabilidade de não aplicação da regra de concordância nominal (.46).

Somados, os resultados desses dois grupos de fatores apontam para uma forte influência do Princípio de Paralelismo Formal, uma vez que marca formal em construção similar precedente implica outra marca formal de pluralidade na construção seguinte; o inverso também é verdadeiro: ausência de marca na construção precedente implica ausência de marca na construção seguinte, em confirmação, portanto, às descobertas de Scherre (1991) para a variedade carioca. Vejamos, todavia, o que pode nos revelar o cruzamento estatístico entre paralelismo formal no discurso e número de marcas precedentes no sujeito e no verbo, conforme disposto na Tabela 6. 


\section{Tabela 6 - Cruzamento entre paralelismo formal no discurso e número de marcas precedentes.}

\begin{tabular}{|c|c|c|c|c|c|c|c|c|c|}
\hline Marcas precedentes & \multicolumn{3}{|c|}{ Uma marca } & \multicolumn{3}{|c|}{ Duas marcas } & \multicolumn{3}{|c|}{ Três ou mais marcas } \\
\hline Paralelismo Formal & Ap. & $\%$ & PR & Ap. & $\%$ & PR & Ap. & $\%$ & $\mathbf{P R}$ \\
\hline Predicativo isolado & $32 / 84$ & 38 & .41 & $61 / 121$ & 50 & .37 & $94 / 126$ & 74 & .53 \\
\hline $\begin{array}{l}\text { Predicativo } 1^{\circ} \text { de uma } \\
\text { série }\end{array}$ & $5 / 16$ & 31 & .26 & $21 / 39$ & 53 & .41 & $29 / 32$ & 90 & .80 \\
\hline $\begin{array}{l}\text { Predicativo precedido de } \\
\text { predicativo c/ plural } \\
\text { explícito }\end{array}$ & $9 / 10$ & 90 & .76 & $29 / 32$ & 90 & .81 & $24 / 25$ & 96 & .89 \\
\hline $\begin{array}{l}\text { Predicativo precedido de } \\
\text { predicativo c/ plural zero }\end{array}$ & $0 / 14$ & 0 & n & $4 / 22$ & 18 & .10 & $2 / 5$ & 40 & .19 \\
\hline
\end{tabular}

Fonte: Elaboração própria.

Esse cruzamento entre dois grupos de fatores internos ou linguísticos é muito revelador no que diz respeito às motivações em jogo para o processo variável de concordância nominal, principalmente nas situações discursivas em que a estrutura predicativa aparece isolada. Era de esperar que houvesse uma relação diretamente proporcional entre o acréscimo no número de marcas precedentes e incidência positiva de marcas formais de plural nos predicativos/particípios passivos.

No entanto, essa expectativa não se confirma. É indiferente que um predicativo isolado apareça numa construção com uma marca ou duas marcas precedentes de plural, já que a probabilidade mais recorrente é a de ausência de marcas formais na estrutura predicativa. Apesar disso, nota-se que a frequência de predicativo isolado com duas marcas precedentes é inferior, em termos de peso relativo, à frequência de predicativo isolado com uma marca precedente. Esse resultado se choca frontalmente com o Princípio de Paralelismo Formal, pois quanto mais marcas precedentes ao predicativo maior deveria ser a chance de ele ser marcado também.

Outra questão instigante diz respeito à situação em que uma construção de predicativo discursivamente isolado contenha três ou mais marcas precedentes. A expectativa mais provável, em termos da aplicação do Princípio de Paralelismo Formal, é a de uma incidência muito mais significativa que .53, peso relativo mais a beirar a neutralidade que a favorecer a marcação explícita. Esse resultado só confirma a hipótese aqui defendida de que há outras motivações regendo o processo de concordância nominal em estruturas predicativas.

Já na situação em que a construção em foco aparece no discurso como a primeira de uma série, a frequência de marcação positiva aumenta progressivamente conforme o número de marcas precedentes. Fica, todavia, sem uma explicação plausível, por que as duas situações parecidas em que uma construção predicativa se identifica como isolada ou como a primeira de uma 
série no discurso dispõem, em construções com três marcas precedentes, de incidências de uso tão desiguais, .53 e .80 respectivamente.

O Princípio de Paralelismo Formal aparece confirmado em duas situações opostas: a que a estrutura predicativa aparece precedida por outra construção formalmente marcada no discurso e por outra construção não formalmente marcada. É totalmente indiferente o número de marcas nessas duas situações, já que a probabilidade de manifestação de plural é alta na primeira e extremamente baixa na segunda. Não seria, no entanto, intuitivamente reveladora, a ideia de que há quem siga a regra normativa de concordância de número e há quem não a siga?

Sobre esses dados pouco confiáveis para uma generalização definitiva sobre a atuação do Princípio de Paralelismo Formal, valeria a pena cruzar os resultados dos fatores internos com um único fator externo, o grau de escolaridade. Esse procedimento se justifica não apenas porque tem peso decisivo sobre a institucionalização da norma culta no Brasil, mas também porque é outra variável independente selecionada pelo programa estatístico juntamente com essas variáveis internas.

Como uma consequência natural de que a variação e a mudança constituem propriedades constitutivas da linguagem (WEINREICH; LABOV; HERZOG, 2006), as forças centrípetas que produzem uniformidade podem, inclusive, levar alguns países a sentir a necessidade de estabelecer princípios de padronização, para determinar que variedades devam ser consideradas mais apropriadas para publicações governamentais, ensino público, uso na mídia e demais instituições públicas. Alguns países atribuem às academias a tarefa de estabelecer os critérios de padronização. Papel importante nesse âmbito tem sido atribuído à L'Académie Française, para determinar o padrão do francês, e La Real Academia Española, para o do espanhol.

A discussão desse assunto enveredou para um campo aparentemente neutro ao se entender a padronização como um procedimento de seleção entre variantes com a finalidade de obter uniformização em alguns usos mais formais da modalidade oral e da modalidade escrita. Entretanto, a noção de padronização tem aspectos simbólicos que ultrapassam muito seus aspectos puramente técnicos e pragmáticos. Mesmo nos casos em que se atribui a padronização ao trabalho das academias, as pessoas passam a acreditar que a língua descrita nas gramáticas e nos dicionários é a única variedade correta para todas as circunstâncias de interação.

A noção de correção, atribuída por algum critério padronizador, é, portanto, entendida como correta num sentido tão absoluto que produz no imaginário popular a ideia de que deixar de usar a variedade padrão equivale a deixar de usar a língua real. O conceito de variedade padrão embutido nesse imaginário é o de que há uma escala que se deve adotar como medida mínima de aceitabilidade. 
A concordância nominal na estrutura predicativa é uma regra no sentido de padrão mínimo baseado em pressões fortemente normativas e a língua representada nas gramáticas mais tradicionais é considerada padrão para uma parcela da população que constitui uma elite sócio-econômica e cultural.

No entanto, a regra representada nas gramáticas de cunho normativo não se baseia na realidade da língua falada em uso na comunidade, modo de ser que instaura um forte sentimento de preconceito social em relação aos que usam uma regra da variedade não padrão, como a de concordância nominal. Essa regra é visivelmente variável, mas não para os que adotam a variedade padrão, que veem a variante não padrão como incorreta e, consequentemente, seus usuários como indivíduos socialmente estigmatizados.

Esse imaginário fornece, portanto, uma forte razão para examinar também o efeito de escolaridade como variável externa, social, em termos da relação mais ou menos proporcional entre grau de adesão aos princípios normativos e grau de escolaridade. A ideia aqui é examinar, primeiramente, o efeito da variável isoladamente para, em seguida, analisar o cruzamento dela com as variáveis internas já discutidas. Iniciemos o percurso pela análise da relação entre marcação de número na estrutura predicativa e grau de escolaridade, conforme mostra a Tabela 7.

Tabela 7 - Relação entre escolaridade e a marcação de pluralidade.

\begin{tabular}{lrrr}
\hline \multicolumn{1}{c}{ Fatores } & Freq. & \% & PR \\
\hline $1^{\circ}$ Ciclo do Ensino Fundamental & $25 / 77$ & 32 & $\mathbf{. 2 8}$ \\
$2^{\circ}$ Ciclo do Ensino Fundamental & $53 / 111$ & 47 & $\mathbf{. 3 7}$ \\
Ensino Médio & $118 / 186$ & 63 & $\mathbf{. 5 4}$ \\
Ensino Superior & $114 / 152$ & 75 & $\mathbf{. 6 5}$ \\
\hline Total & $310 / 526$ & 59 & $\mathbf{. 5 9 5}$ (input) \\
\hline
\end{tabular}

Fonte: Elaboração própria.

Os resultados da Tabela 7 permitem concluir que a incidência de marcas no predicativo é diretamente proporcional ao acréscimo de grau de escolaridade, mas com uma nítida linha divisória, em termos estatísticos, entre estar no primeiro e no segundo ciclo do ensino fundamental e estar no ensino médio e no superior. A primeira situação praticamente desfavorece o uso de marcas de plural e a segunda situação favorece uma probabilidade maior de aplicação da regra de concordância de número e em escala ascendente.

A razão da maior probabilidade de adoção da regra padrão de concordância pelos informantes com nível médio e superior de ensino está certamente arraigada no contato maior que esses indivíduos mantêm com a atividade 
normativa e que se aplica como uma injunção prescritiva rigorosa no sistema escolar. Uma ressalva necessária: embora seja elevada a incidência de aplicação positiva, a frequência estatística de .65 é uma demonstração clara de que, nos predicativos, a regra não é apenas variável para os indivíduos de ensino superior, mas também que está muito distante do estatuto de regra categórica.

O Princípio de Paralelismo Formal é claramente definível como uma motivação propriamente interna e, como tal, a aplicação da regra de concordância nominal passaria, então, a ser um procedimento meramente mecânico, determinado por mecanismos puramente estruturais. Como, todavia, acabamos de ver que, para a variedade riopretense, a escolaridade de ensino médio representa uma fronteira significativa a separar os que tendem à marcação positiva dos que tendem à marcação negativa, parece muito instrutivo verificar a interação entre uma motivação linguística como o Princípio de Paralelismo Formal e uma motivação extralinguística, aqui restrita à escolaridade.

Uma hipótese que logo se coloca é se o paralelismo formal - marca levando a marca e ausência levando a ausência - não poderia representar, ao menos para a variedade investigada, uma implicação social cuja distribuição refletiria, na realidade, uma relação proporcional do seguinte tipo: o comportamento linguístico dos indivíduos de $1^{\circ}$ e $2^{\circ}$ ciclos do ensino fundamental favoreceria ausência de marcas, enquanto o dos indivíduos com ensino médio e superior, a presença de marcas. Continuando, então, o percurso, é necessário, refletir agora sobre a relação entre motivações de natureza diversa competindo entre si. Além disso, o cruzamento de fatores internos com externos tem a finalidade de verificar a possível influência de escolaridade sobre o Princípio de Paralelismo Formal.

O cruzamento com escolaridade limita-se aqui a dois parâmetros internos do paralelismo formal, da perspectiva intraoracional, a saber, características formais do verbo e número de marcas precedentes, e a um parâmetro interno da dimensão interoracional, que é o paralelismo formal no discurso.

E o primeiro passo dessa trajetória está na distribuição entre uma dimensão do paralelismo formal - características formais do verbo e escolaridade, exposta na Tabela 8. 
Tabela 8 - Características formais do verbo e escolaridade.

\begin{tabular}{lrrrrrrrrr}
\hline $\begin{array}{c}\text { Características } \\
\text { formais do verbo }\end{array}$ & \multicolumn{3}{c}{ Zero verbal } & \multicolumn{4}{c}{ Verbo marcado } & \multicolumn{3}{c}{ Verbo não marcado } \\
\hline \multicolumn{1}{c}{ Escolaridade } & Ap. & $\mathbf{0}$ & $\mathbf{P R}$ & Ap. & $\mathbf{\%}$ & PR & Ap. & \% & PR \\
\hline $1^{\circ}$ ciclo EF & $2 / 2$ & 100 & $\mathbf{n}$ & $23 / 54$ & 42 & $\mathbf{. 3 2}$ & $0 / 21$ & 0 & $\mathbf{n}$ \\
$2^{\circ}$ ciclo EF & $3 / 6$ & 50 & $\mathbf{. 3 9}$ & $48 / 81$ & 59 & $\mathbf{. 4 8}$ & $2 / 24$ & 08 & $\mathbf{. 0 5}$ \\
Ensino Médio & $7 / 10$ & 70 & $\mathbf{. 6 0}$ & $109 / 152$ & 71 & $\mathbf{. 6 2}$ & $2 / 24$ & 08 & $\mathbf{. 0 5}$ \\
Ensino Superior & $3 / 4$ & 75 & $\mathbf{. 6 5}$ & $108 / 139$ & 77 & $\mathbf{. 6 9}$ & $3 / 9$ & 33 & $\mathbf{. 2 4}$ \\
\hline
\end{tabular}

Fonte: Elaboração própria.

Os resultados confirmam haver uma relação diretamente proporcional entre escolaridade e presença de marcas, mas apenas nas situações em que o verbo aparece marcado positivamente. Embora o resultado seja o mesmo nas situações em que o fenômeno em análise é precedido por um zero verbal, a incidência da aplicação é muito pouco significativa para ser possível tirar conclusões definitivas.

Como tendência, pode-se notar que os dados, vistos sob uma orientação vertical de leitura, mostram que as situações de zero verbal e de verbo com marca de plural representam uma nítida linha divisória a separar o comportamento dos informantes que dispõem de ensino fundamental dos que dispõem de ensino médio e superior. Aqueles apresentam um uso reduzido de marcas formais em formas de estrutura predicativa precedidas por verbos marcados, conforme atestam os exemplos (8a-b), enquanto estes apresentam comportamento inverso, com uma incidência elevada de marcação de plural nas estruturas predicativas, conforme atestam os exemplos (9a-b).

(8) a eu acho que hoje as meninas ficam mocinha muito depressa né? (AC 096/RO/L 403)〉)

b (...) Eles que num num são realista num são verdade(i)ro... mas são muito falso (AC 029/RO/L 185)

(9) a (...) a sala de aula de terce(i)ra e quarta séries são salas onde não existe alfabeto... porque os alunos já estão alfabetizados... (AC 88/ DE/L 335-336)

b (...) que:: na época é a:: vaga era pra uma pessoa... mas das três pessoas... duas foram consideradas aptas (AC 114/NE L 55-56)

É, todavia, um tanto diferente o comportamento dos informantes nas situações em que o fenômeno em análise é precedido por um verbo não marcado 
em número. Poucos informantes da amostra, até mesmo os dotados de ensino médio e superior, mostram tendência pela marcação positiva. Essa situação específica, na qual a diferença de grau de escolaridade não parece exercer influência, parece apontar para a independência da gramática em relação aos fatores externos, mais especificamente, para confirmação do Princípio de Paralelismo Formal.

No entanto, também esses resultados precisam ser relativizados, já que o número de ocorrências, extremamente reduzido, pode mascarar uma interpretação mais qualitativa, exatamente como deve ser relativizada a aparente influência de escolaridade sobre a situação de predicativos precedidos por zero verbal.

Passemos agora para o outro cruzamento entre número de marcas precedentes e escolaridade, que aparece na Tabela 9.

Tabela 9 - Cruzamento entre marcas precedentes e escolaridade.

\begin{tabular}{lrrrrrrrrr}
\hline Marcas precedentes & \multicolumn{3}{c}{ Uma marca } & \multicolumn{3}{c}{ Duas marcas } & \multicolumn{3}{c}{ Três ou mais marcas } \\
\hline \multicolumn{1}{c}{ Escolaridade } & Ap. & $\mathbf{\%}$ & PR & Ap. & $\mathbf{\%}$ & PR & Ap. & \% & PR \\
\hline $1^{\circ}$ ciclo EF & $2 / 23$ & 08 & $\mathbf{. 1 4}$ & $16 / 39$ & 41 & $\mathbf{. 2 9}$ & $7 / 15$ & 46 & $\mathbf{. 3 4}$ \\
$2^{\circ}$ ciclo EF & $6 / 33$ & 18 & $\mathbf{. 2 0}$ & $20 / 44$ & 45 & $\mathbf{. 3 7}$ & $27 / 34$ & 79 & $\mathbf{. 5 6}$ \\
Ensino Médio & $22 / 45$ & 48 & $\mathbf{. 3 8}$ & $42 / 74$ & 56 & $\mathbf{. 5 2}$ & $54 / 67$ & 80 & $\mathbf{. 6 6}$ \\
Ensino Superior & $16 / 23$ & 69 & $\mathbf{. 6 8}$ & $37 / 57$ & 64 & $\mathbf{5 7}$ & $61 / 72$ & 84 & $\mathbf{. 7 6}$ \\
\hline
\end{tabular}

Fonte: Elaboração própria.

Essa disposição de dados fornece algumas deduções relevantes. Em primeiro lugar, os resultados revelam um aumento progressivo de marcas formais, que contempla uma relação diretamente proporcional ao acréscimo de grau de escolaridade. Em segundo lugar, quanto maior o número de marcas precedentes, tanto maior a probabilidade de a estrutura predicativa receber marca formal de pluralidade. Em terceiro lugar, é certo que essas correlações são motivadas por escolaridade.

Prosseguindo na trajetória expositiva, passemos agora a ver a relação entre a dimensão discursiva do paralelismo formal e o grau de escolaridade, cujos resultados aparecem distribuídos na Tabela 10. 
Tabela 10 - Paralelismo formal no discurso e escolaridade.

\begin{tabular}{lccccccccccccc}
\hline \multicolumn{1}{c}{ Escolaridade } & $1^{\circ}$ ciclo EF & \multicolumn{3}{c}{$2^{\circ}$ ciclo EF } & \multicolumn{1}{c}{ Ensino Médio } & \multicolumn{3}{c}{ Ensino Superior } \\
\hline $\begin{array}{l}\text { Paralelismo } \\
\text { formal no } \\
\text { discurso }\end{array}$ & $\mathbf{A p .}$ & $\mathbf{\%}$ & $\mathbf{P R}$ & $\mathbf{A p .}$ & $\mathbf{\%}$ & $\mathbf{P R}$ & $\mathbf{A p .}$ & $\mathbf{\%}$ & $\mathbf{P R}$ & $\mathbf{A p .}$ & $\mathbf{\%}$ & $\mathbf{P R}$ \\
\hline $\begin{array}{l}\text { Predicativo } \\
\text { isolado }\end{array}$ & $11 / 42$ & 26 & $\mathbf{. 1 8}$ & $28 / 41$ & 40 & $\mathbf{. 3 0}$ & $76 / 123$ & 61 & $\mathbf{. 5 0}$ & $72 / 93$ & 77 & $\mathbf{. 6 8}$ \\
$\begin{array}{l}\text { Predicativo } \\
\text { primeiro de uma } \\
\text { série }\end{array}$ & $7 / 16$ & 43 & $\mathbf{. 3 3}$ & $12 / 19$ & 63 & $\mathbf{. 5 2}$ & $18 / 27$ & 66 & $\mathbf{. 5 5}$ & $18 / 25$ & 72 & $\mathbf{. 6 1}$ \\
$\begin{array}{l}\text { Pred. precedido } \\
\text { de pred. c/ plural } \\
\text { explícito }\end{array}$ & $6 / 7$ & 85 & $\mathbf{. 7 9}$ & $13 / 13$ & 100 & $\mathbf{n}$ & $22 / 23$ & 95 & $\mathbf{. 9 3}$ & $21 / 24$ & 87 & $\mathbf{. 8 1}$ \\
$\begin{array}{l}\text { Predicativo } \\
\text { precedido de } \\
\text { pred.c/ plural zero }\end{array}$ & $1 / 12$ & 08 & $\mathbf{. 0 5}$ & $0 / 8$ & 0 & $\mathbf{n}$ & $2 / 11$ & 18 & $\mathbf{. 1 2}$ & $3 / 10$ & 30 & $\mathbf{. 2 1}$ \\
\hline
\end{tabular}

Fonte: Elaboração própria.

Na situação em que a construção predicativa está isolada no discurso ou aparece pela primeira vez em uma série, o comportamento linguístico dos informantes dos dois ciclos do Ensino Fundamental tende para um uso reduzido de adesão às normas da variedade padrão, enquanto o dos informantes de Ensino Médio e Superior tende para a adesão às normas. Enfim, estar no Ensino Superior é condição favorável para o emprego da flexão de plural nesse tipo de estrutura.

Um fato interessante a observar aqui é que, contrariamente aos informantes de outros níveis de escolaridade, os do Ensino Superior tendem para uma frequência maior de uso nas situações de estrutura predicativa isolada do que nas de estrutura predicativa primeira de uma série. O que há de interessante nessa distribuição está justamente no fato de compartilharem a mesma estrutura frasal, cuja configuração é SN sujeito, verbo e predicativo, como se vê nos exemplos (10a-b), com predicativos isolados, e (11a-b), com predicativos primeiro de uma série, respectivamente.

(10) a a sala de aula de terce(i)ra e quarta séries são salas onde não existe alfabeto... porque os alunos já estão alfabetizados... (AC 88/DE/L 335-336)

b (...) e ela abandonô(u) ela foi embora não aguentô(u)... veja bem o quanto que... que esses filhos e esse marido foi ruim pra ela... (AC 110/NR/L 162-163) 
(11) a minhas tia são muito católica em José Bonifácio mas são assim beata mesmo sabe?... se soubé(r) de um negócio desse ela me mata... (AC 100/RO/L 380)

b (...) ele tem:.... os bancos dele são diferentes também... foram trocados... não são originais... pra ficá dá um aspecto mais esporte... (AC 049/DE/L 132-133)

Vistos de uma perspectiva horizontal, os dados da tabela 10 apontam para uma correlação diretamente proporcional entre acréscimo de escolaridade e acréscimo no uso de marcas formais.

Outro aspecto notável está nos resultados referentes às situações impermeáveis à diferença de escolaridade, que são as de estrutura predicativa precedida de estrutura predicativa com plural explícito e com marcação zero. Na primeira situação, o comportamento é, de certa forma, linear, cuja incidência recai sobre pesos relativos acima de .79, com diferenças reduzidas entre os agrupamentos sociais. Na segunda situação, também os resultados se mostram indiferentes a diferenças de escolaridade, mas a incidência de adesão às formas normativamente reguladas é extremamente baixa por agrupamento social, não ultrapassando a marca de .21 para os informantes no topo do sistema de ensino.

De qualquer modo, os índices de aplicação são extremamente baixos para que seja confiável uma generalização do tipo marca leva a marca e ausência leva a ausência, que confirmaria o princípio do paralelismo formal.

\section{Considerações finais}

Ao longo deste trabalho, estabelecemos como objetivo desvendar se a marcação de número nas estruturas de SNs e SAs predicativas poderia ser explicada por motivações tipicamente formais, ou tipicamente funcionais, ou ainda, pela devida interação entre esses dois tipos de motivações, competindo entre si.

A análise dos resultados mostra, por um lado, que os princípios funcionais, como o princípio de economia (HAIMAN, 1983) e a Condição de Distintividade (KIPARSKY, 1972), atuam na marcação de pluralidade, mas não têm força suficiente para governar todo o processo na variedade estudada. Mostram, por outro, que as motivações formais, gerenciadas pelo Princípio de Paralelismo Formal, também exercem influência significativa na marcação explícita de pluralidade nos dois fenômenos. Similarmente com o que ocorre com as motivações funcionais, 
também as motivações formais não atuam categoricamente de modo a regerem solitariamente o fenômeno como têm mostrado os estudos de outras variedades.

A atuação do Princípio de Paralelismo Formal, na variedade estudada, sofre severa restrição da condição social dos usuários da variedade, especialmente, a formação escolar; desse modo, ao menos no que tange à variedade investigada, não é possível dar a esse princípio o poder explanatório que lhe atribui Labov (1994), isto é, o de que a pluralidade tem uma motivação essencialmente interna, derivada da própria configuração formal do sistema gramatical, que governa, neste caso específico, a variedade riopretense. Por essa razão, a explicação mais plausível para a marcação de pluralidade nos predicativos é a de que há motivações em competição, nos termos de Du Bois (1985) e é a marcação de pluralidade o "bem limitado", pelo qual forças múltiplas, as motivações formais ou internas e funcionais ou externas, competem entre si.

CAMACHO, R. G.; SALOMÃO, M. H. Competing motivations in sociolinguistic variation: the plural in NP and AP predicates in the São José do Rio Preto Spoken Variety. Alfa, São Paulo, v.56, n.3, p.1055-1087, 2012.

- ABSTRACT. THE MAIN PURPOSE OF THIS PAPER IS TO SUBJECT TO A SOCIOLINGUISTIC QUANTITATIVE-BASED TREATMENT SOME DATA OF VARIABLE PLURAL MARKING IN PREDICATE NPS AND APS EXTRACTED FROM A SAMPLE OF SPOKEN LANGUAGE COLLECTED IN THE REGION OF SÃO JOSÉ DO RIO PRETO. A MORE SPECIFIC AIM IS TO EXAMINE WHETHER THE BEST EXPLANATION FOR VARIABLE MARKING OF PLURAL CAN BE BASED ON EITHER EXCLUSIVELY FORMAL OR EXCLUSIVELY FUNCTIONAL CONSTRAINTS, OR PERHAPS BASED ONTHE INTERACTION BETWEENBOTH OFTHEM, WHICH WOULD CONSIST IN TRULY COMPETING MOTIVATIONS (DU BOIS, 1985). THE RESULTS SHOW THAT NEITHER FUNCTIONAL NOR FORMAL MOTIVATIONS ALONE RULE THE PHENOMENON, WHICH HAPPENS TO BE STRONGLY CONSTRAINED BY A SPECIFIC EXTERNAL FACTOR: education level. That is why the most likely explanation for plural marking in predicates is that there are competing motivations, which is a term used by Du Bois (1985), and plural markings are the "limited means", for which multiple forces, the formal or internal and the functional or external motivations, compete among themselves.

- KEYWORDS: Functionalism. Formalism. Plurality. Nominal agreement. Predicate.

\section{REFERÊNCIAS}

BRAGA, M. L. A concordância de número no sintagma nominal no Triângulo Mineiro. 1977. 88f. Dissertação (Mestrado em Linguística) - Departamento de Letras, Pontifícia Universidade Católica, Rio de Janeiro, 1977.

CAMACHO, R. G. Motivações formais e funcionais da marcação de pluralidade no português falado na região de São José do Rio Preto. 2008. 110f. Relatório Científico FAPESP, São José do Rio Preto, 2008. 
O formal e o funcional na teoria variacionista. In: RONCARATI, C.; ABRAÇADO, J. (Org.). Português brasileiro: contato linguístico, heterogeneidade e história. Rio de Janeiro: Viveiros de Castro Editora, 2003. p.55-65.

DIAS, J. F. V. A concordância de número nos predicativos e nos particípios passivos na fala da região sul: um estudo variacionista. 1996. 124f. Dissertação (Mestrado em Comunicação) - Universidade Federal de Santa Catarina, Florianópolis, 1996.

DIK, S. C. The theory of functional grammar: part I: the structure of the clause. 2nd rev. ed. Berlin: Mouton de Gruyter, 1997. (Série Functional grammar series ; 9).

DU BOIS, J. W. Competing motivations. In: HAIMAN, J. Iconicity in syntax. Amsterdam: John Benjamins, 1985. p.342-365.

FIAMENGUI, A. H. R. A marcação de pluralidade no SN na fala e na escrita de adolescentes da região de São José do Rio Preto. 2011. 144f. Dissertação (Mestrado em Estudos Linguísticos) - Universidade Estadual Paulista, São José do Rio Preto, 2011.

GARCÍA, E. C. Shifting variation. Lingua, Amsterdam, v.67, p.189-224, 1985.

GONÇALVES, S. C. L. O português falado na região de São José do Rio Preto: constituição de um banco de dados anotado para o seu estudo. Relatório científico parcial III apresentado à FAPESP, Universidade Estadual Paulista, São José do Rio Preto, 2007. Disponível em: <http://www.iboruna.ibilce.unesp.br/histórico/ relatorio3>. Acesso em: 16 out. 2011.

GONÇALVES, S. C. L.; TENANI, L. E. Problemas teórico-metodológicos na elaboração de um sistema de transcrição de dados interacionais: o caso do projeto ALIP Amostra Linguística do Interior Paulista. Gragoatá, Niterói, v.25, p.165-184, 2008.

GUY, G. Linguistic variation in Brazilian Portuguese: aspects of the phonology, syntax and language history. 1981. 391f. Tese (Doutorado em Linguística) Universidade da Pennsylvania, Phildelphia, 1981.

HAIMAN, J. Iconic and economic motivation. Language, Baltimore, v.59, p.781819, 1983.

HOCHBERG, J. G. Functional compensation for /s/ deletion in Puerto Rican Spanish. Language, Baltimore, v.62, n.3, p.609-621, set. 1986.

KIPARSKY, P. Explanation in phonology. In: PETERS, S. (Ed.) Goals of linguistic theory. Englewood Cliffs: Prentice-Hall, 1972. p.189-227.

LABOV,W. Principles of linguistic change. Oxford: Basil Blackwell, 1994. (Internal factors; v.1). 
The overestimation of functionalism. In: DIRVEN, R.; FRIED, V. (Ed.). Functionalism in linguistics. Amsterdam: John Benjamins, 1987. p.311-32.

.Where does the linguistic variable stop? a response to Beatriz Lavandera. Working Papers in Sociolinguistics, Austin, v.44, 1978.

. Sociolinguistic patterns. Pennsylvania: University of Pennsylvania Press, 1972.

LAVANDERA, B. R. Where does the sociolinguistic variable stop? Language in Society, Cambridge, v.7, p.171-82, 1978.

LEFEBVRE, C. Variation in plural marking: the case of cuzco quechua. In: SANKOFF, D.; CEDERGREN, H. (Ed.).Variation Omnibus. Canadá: Linguistic Research, 1981. p.73-84.

POPLACK, S. Delection and disambiguation in Puerto Rican Spanish. Language, Baltimore, v. 56, n. 2, p.371-385, 1980.

ROMAINE, S. The status of variable rules in sociolinguistic theory. Journal of LinguisticS, Cambridge, v.17, p.93-119, 1981.

RONCARATI, C. Banco de dados interacionais. Rio de Janeiro: Universidade Federal do Rio Janeiro, 1996.

RUBIO, C. F. Padrões de concordância verbal e de alternância pronominal no português brasileiro e europeu: estudo sociolinguístico comparativo. 2012. $392 \mathrm{f}$. Tese (Doutorado em Estudos Linguísticos) - Universidade Estadual Paulista, São José do Rio Preto, 2012

A concordância verbal na região noroeste do Estado de São Paulo. 2008. 152f. Dissertação (Mestrado em Estudos Linguísticos) - Universidade Estadual Paulista, São José do Rio Preto, 2008.

SALOMÃO, M. H. A variação de pluralidade nas estruturas predicativas da variedade falada na região de São José do Rio Preto. 2010. 162f. Dissertação (Mestrado em Estudos Linguísticos) - Universidade Estadual Paulista, São José do Rio Preto, 2010.

SANKOFF, D.; TAGLIAMONTE, S.; SMITH, E. Goldvarb X: a variable rule application for Macintosh and Windows. University of Toronto, Department of Linguistics, 2005. Software. Disponível em: <http://individual.utoronto.ca/ tagliamonte/goldvarb.htm>. Acesso em: 16 out. 2011.

SAUSSURE, F. Curso de linguística geral. Tradução de Antônio Chelini, José Paulo Paes e Izidoro Blikstein. São Paulo: Cultrix, 1977.

SCHERRE, M. M. P. Aspectos da concordância de número no português do Brasil. Revista Internacional de Língua Portuguesa, Pelotas, v.12, p.37-49. 1994. 
. A concordância de número nos predicativos e nos particípios passivos. Organon, Porto Alegre, v.5, n.17, 1991. Reanálise da concordância nominal em português. 1988. 555f. Tese (Doutorado em Linguística) - Faculdade de Letras, Universidade Federal Rio de Janeiro, Rio de Janeiro, 1988.

TERREL, T. Functional constraints on deletion of word-final/s/ in Cuban Spanish. Berkeley Linguistics Society, Berkeley, v.1, p.431-7, 1975.

WEINER, E. J.; LABOV, W. Constraints on the agentless passive. Journal of Linguistics, Cambridge ,v.19, p.29-58, 1983.

WEINREICH, U.; LABOV, W.; HERZOG, M. I. Fundamentos empíricos para uma teoria da mudança linguística. Tradução de Marcos Bagno e Carlos Alberto Faraco. São Paulo: Parábola, 2006.

Recebido em março de 2012

Aprovado em agosto de 2012 